\title{
Políticas públicas en comunicación
}

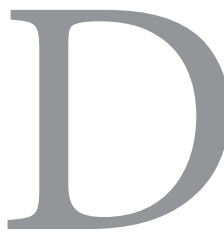

esde la conformación de los Estados nacionales se han desarrollado políticas públicas de comunicación cuyo objetivo ha sido defender y fomentar valores públicos y desarrollar la industria cultural. Con el surgimiento de cada nuevo tipo de medios ha habido una rediscusión de esas políticas públicas para intentar canalizar el nuevo impacto social.

Las corrientes políticas se diferencian entre sí en gran medida por su diferente visión de los medios de comunicación y por cómo estos deben ser o no regulados. En los últimos años, en casi todos los países de América Latina ha sido muy intensa la discusión sobre estas políticas públicas y en varios de ellos hubo una redefinición del marco regulatorio, que está dando sus primeros pasos.

En la Argentina, el fallo reciente de la Corte Suprema de Justicia a favor de la constitucionalidad de Ley de Servicios de Comunicación Audiovisual (LSCA), aprobada en 2009 por el Congreso, muestra la vigencia del tema y la variedad de enfoques desde el campo académico.

María Soledad Segura estudia el nuevo espacio de posibilidades y desafíos que, para los medios del sector social, abre la LSCA. Por medio del estudio de los discursos de sus actores y sus asociaciones, Segura traza las estrategias y las prácticas particulares en su relación con el Estado, desde las formas de la cooperación hasta las de la disputa, desde las alianzas hasta la autonomía y la confrontación, sin perder de vista en ningún caso el reclamo por la efectivización del espacio previsto para el sector social.

Santiago Marino realiza un un recorrido por las políticas públicas de comunicación del sector audiovisual (TV y cine) en la Argentina, en su compleja trama de aspectos (políticas gubernamentales, producción, distribución y exhibición; sustentabilidad, contenidos).

Natalia Aruguete revisa el corpus bibliográfico que ha estudiado la influencia mutua entre la agenda política y la agenda mediática, y los rastros que esta interacción o simbiosis deja en los textos noticiosos.

Los textos presentados en este monográfico de Austral Comunicación enriquecen el debate generado en torno a las políticas públicas que ven en la comunicación una aliada estratégica para llevar adelante sus propósitos. 